\title{
Identification of the Allergenic Ingredients in Reduning Injection by Ultrafiltration and High-Performance Liquid Chromatography
}

\author{
Fang Wang, ${ }^{1}$ Cun-yu Li,, ${ }^{1,2}$ Yun-feng Zheng, ${ }^{1}$ Hong-yang Li, ${ }^{1}$ \\ Wei Xiao, ${ }^{3}$ and Guo-ping Peng ${ }^{1,2}$ \\ ${ }^{1}$ College of Pharmacy, Nanjing University of Chinese Medicine, Nanjing 210023, China \\ ${ }^{2}$ Collaborative Innovation Center of Chinese Medicinal Resources Industrialization, Jiangsu, China \\ ${ }^{3}$ Jiangsu Kanion Pharmaceutical Co., Ltd., China
}

Correspondence should be addressed to Guo-ping Peng; guopingpeng@sohu.com

Received 10 November 2015; Accepted 8 February 2016

Academic Editor: Nejat K. Egilmez

Copyright (C) 2016 Fang Wang et al. This is an open access article distributed under the Creative Commons Attribution License, which permits unrestricted use, distribution, and reproduction in any medium, provided the original work is properly cited.

Reduning injection is a traditional Chinese medicine injection which has multiple functions such as clearing heat, dispelling wind, and detoxification. Although Reduning injection was widely utilized, reports of its allergenicity emerged one after another. However, there is little research on its allergenic substances. The aim of this study is to evaluate the sensitization of Reduning injection and explore the underlying cause of the anaphylactic reaction. The main ingredients in Reduning injection were analyzed before and after ultrafiltration. Ultrafiltrate Reduning injection, unfiltered Reduning injection, egg albumin, Tween-80, and nine effective components in Reduning injection were utilized to sensitize guinea pigs. The serum 5-hydroxytryptamine level was used to assess the sensitization effect of Reduning injection. We found a significant decrease in Tween-80 content comparing to other components in the injection after ultrafiltration. Unfiltered Reduning injection, Tween-80, chlorogenic acid, and cryptochlorogenin acid caused remarkable anaphylactoid reaction on guinea pigs while ultrafiltration Reduning resulted in a significantly lower degree of sensitization. Our results suggest that ultrafiltration could significantly reduce the sensitization of Reduning injection, which is likely due to the decrease of Tween-80. We also conjectured that the form of chlorogenic acid and cryptochlorogenin acid within the complex solution mixture may also affect the sensitizing effect.

\section{Introduction}

Reduning injection is a traditional Chinese medicine (TCM) injection refined from three Chinese herbal medicines, namely, honeysuckle, gardenia, and abrotani herba, and formulated for injection [1,2]. This injection has multiple functions such as clearing heat, dispelling wind, and detoxification [3]. It is clinically used in the treatment of hyperpyrexia, slight aversion to cold, head and body pain, cough, yellow sputum, and other symptoms caused by respiratory tract infection (with external wind heat syndrome) $[4,5]$. From the time Reduning injection was listed as a clinical treatment, it has been widely utilized with good clinical efficacy. However, there are also a few reports of severe anaphylaxis during the clinical application [6]. It is known that Reduning injection mainly contains Tween-80, chlorogenic acid, geniposide, caffeic acid, cryptochlorogenin acid, isochlorogenic acid (A, B, and C), neochlorogenic acid, and secoxyloganin [7-10]. Previous studies have shown that some components in TCM injections might be the cause of the allergic reaction and anaphylactoid reaction [11-13]. However, the specific compound responsible for the allergic reaction is still not clear.

Ultrafiltration is a separation technique in which a porous membrane is used as filtering medium and the molecules are separated according to their size [14]. After ultrafiltration, macromolecules such as pyrogen, microbes, proteins, pigments, resin, and tannin are excluded [15]. In this study, we used ultrafiltration to separate the compounds in Reduning injection to explore the cause of anaphylaxis. 
Previous studies have identified some key cytokines are the mediator of antibody-mediated systemic anaphylaxis [1618] and our studies had shown that 5-hydroxytryptamine (5-HT) can be detected rapidly by high-performance liquid chromatography (HPLC) and can be used as an index for anaphylaxis [19]. In our study, guinea pig plasma 5-HT level was measured to determine the sensitization of Reduning injection before and after ultrafiltration. Furthermore, the components in the injection were also analyzed to determine the main allergens in Reduning injection.

\section{Materials and Methods}

2.1. Animals. A total of 140 male guinea pigs were purchased from Nanjing Qinglongshan Animal Breeding Center. All animals were housed at $22^{\circ} \mathrm{C}$ and $55 \% \pm 5 \%$ relative humidity. All experiments were carried out according to the guidelines of the Animal Care Committee of Nanjing University of Chinese Medicine.

2.2. Reagents and Materials. Egg albumin and 5-HT were purchased from Sigma (St. Louis, USA). Chloral hydrate was purchased from Sinopharm Chemical Reagent Co., Ltd. (Shanghai, China). Heparin sodium injection was purchased from Jiangsu Wangbang Pharmaceutical Co., Ltd. (Jiangsu, China). Heptanesulfonate sodium was purchased from J\&K Chemical Ltd. (Shanghai, China). Sodium dihydrogen phosphate was purchased from Shantou Xilong Chemical Industry Factory Co., Ltd. (Guangdong, China). Ethylene Diamine Tetraacetic Acid (EDTA) was purchased from Shanghai Fuqi Industrial \& Trading Co., Ltd. (Shanghai, China). Sodium chloride injection was purchased from Anhui Fengyuan Pharmaceutical Co., Ltd. (Anhui, China).

Reduning injection was purchased from Jiangsu Kangyuan Pharmaceutical Co., Ltd. (Jiangsu, China), the batch numbers are 120211, 120209, and 120703. Tween-80 was purchased from Sigma (St. Louis, USA), the batch number is 018K00941. Chlorogenic acid was purchased from China Institute of pharmaceutical and biological products (Beijing, China); the batch number is 0753-9909. Geniposide was purchased from National Institute for Food and Drug Control (Beijing, China); the batch number is 110885-200102. Neochlorogenic acid and cryptochlorogenin acid were purchased from Shanghai Yuanye Technology Co., Ltd. (Shanghai, China); the batch numbers are PA0819RA13 and ZF0226BA14. Isochlorogenic acid A, isochlorogenic acid B, isochlorogenic acid $\mathrm{C}$, and secoxyloganin reference substance were produced in-house and possessed a purity above $98 \%$ as tested by chromatography. The ultrafiltration column was purchased from Millipore Corporation (Massachusetts, USA).

2.3. Solutions Preparation. Egg albumin solution was dissolved in saline to a concentration of $5.0 \mathrm{mg} / \mathrm{mL}$. Tween- 80 was prepared to $1 \% \mathrm{v} / \mathrm{v}$ by dissolving $1 \mathrm{~mL}$ of Tween- 80 in saline.

Standard solutions of chlorogenic acid, neochlorogenic acid, cryptochlorogenin acid, geniposide, caffeic acid, isochlorogenic acid $\mathrm{A}$, isochlorogenic acid $\mathrm{B}$, isochlorogenic
TABLE 1: Elution gradient program.

\begin{tabular}{lcc}
\hline Time/min & Methyl alcohol\% & $0.1 \%$ formic acid-water \\
\hline 0 & 12 & 88 \\
20 & 30 & 70 \\
60 & 45 & 55 \\
\hline
\end{tabular}

acid $\mathrm{C}$, and secoxyloganin were prepared in saline, and their concentrations were $6.0 \mathrm{mg} / \mathrm{mL}, 3.7 \mathrm{mg} / \mathrm{mL}, 3.3 \mathrm{mg} / \mathrm{mL}$, $7.0 \mathrm{mg} / \mathrm{mL}, 0.3 \mathrm{mg} / \mathrm{mL}, 0.3 \mathrm{mg} / \mathrm{mL}, 0.6 \mathrm{mg} / \mathrm{mL}, 0.5 \mathrm{mg} / \mathrm{mL}$, and $1.0 \mathrm{mg} / \mathrm{mL}$, respectively. The concentrations are equal to their respective concentrations in the Reduning injection.

After equilibration with two column volumes of Reduning injection, the ultrafiltration column with a molecular weight cut-off of 2,000 Da was used to filter the Reduning injection.

\subsection{Detection of Major Components in Reduning Injection before and after Ultrafiltration}

2.4.1. Simultaneous Detection of Chlorogenic Acid, Neochlorogenic Acid, Cryptochlorogenin Acid, Geniposide, Caffeic Acid, Isochlorogenic Acid A, Isochlorogenic Acid B, Isochlorogenic Acid C, and Secoxyloganin. Waters e2695 liquid chromatograph equipped with a Waters $2489 \mathrm{UV} /$ visible light detector (Massachusetts, USA) was utilized for detection. The ODS$\mathrm{C} 18(4.6 \mathrm{~mm} \times 150 \mathrm{~mm}, 5 \mu \mathrm{m})$ column was used with a flow rate of $1.0 \mathrm{~mL} / \mathrm{min}$ at a column temperature of $30^{\circ} \mathrm{C}$. The mobile phases were methyl alcohol and $0.1 \%$ formic acidwater. The elution gradient program is shown in Table 1 . The detection wavelength was $238 \mathrm{~nm}$.

2.4.2. Detection of Tween-80. Waters e2695 liquid chromatograph equipped with an Alltech evaporative light scattering detection 2000 detector (Kentucky, USA) was used for detection. A TSK-GEL G2000 SWXL $(7.8 \mathrm{~mm} \times 300 \mathrm{~mm}$, $5 \mu \mathrm{m})$ column was used for separation. The mobile phases were $5.0 \mathrm{mmol} \cdot \mathrm{L}^{-1}$ ammonium acetate : acetonitrile $(90: 10)$, $\mathrm{pH}=4.0$, and column temperature was $30^{\circ} \mathrm{C}$. Flow rate was $0.6 \mathrm{~mL} \cdot \mathrm{min}^{-1}$ and the injection volume was $10 \mu \mathrm{L}$. As for the ELSD condition, the drift tube temperature was set at $110^{\circ} \mathrm{C}$ and nitrogen flow rate was set at $2.3 \mathrm{~L} \cdot \mathrm{min}^{-1}$.

2.5. Calculation of Componential Transmittance. The percentage of retention of each component following ultrafiltration was calculated according to

$$
R=\frac{C_{f}}{C_{s}} \times 100 \%,
$$

where $R$ is the percentage of retention of the component, $C_{f}$ is the concentration of components in filtrate $(\mathrm{mg} / \mathrm{mL})$, and $C_{s}$ is the concentration of components in stock solution $(\mathrm{mg} / \mathrm{mL})$.

2.6. Animal Experiments. A total of 140 male guinea pigs with bodyweight of $300 \pm 50$ g were randomly divided into 
TABLE 2: Regression equation, linear range, and correlation coefficient of investigated compounds.

\begin{tabular}{lcccc}
\hline Serial number & Component name & Regression equation & Correlation coefficient $(r)$ & Linear range $(\mathrm{mg} / \mathrm{mL})$ \\
\hline 1 & Neochlorogenic acid & $Y=13.223 X-6.236$ & 0.9989 & $0.05 \sim 5.05$ \\
2 & Chlorogenic acid & $Y=10.758 X+20.156$ & 0.9998 & $0.04 \sim 10.00$ \\
3 & Cryptochlorogenin acid & $Y=10.002 X+5.3598$ & 0.9991 & $0.05 \sim 6.12$ \\
4 & Caffeic acid & $Y=20.339 X+10.856$ & 0.9995 & $0.01 \sim 4.22$ \\
5 & Geniposide & $Y=5.673 X+14.982$ & 0.9993 & $0.05 \sim 10.06$ \\
6 & Secoxyloganin & $Y=12.912 X-5.32$ & 0.9992 & $0.04 \sim 5.22$ \\
7 & Isochlorogenic acid B & $Y=14.008 X+20.703$ & 0.9987 & $0.01 \sim 3.00$ \\
8 & Isochlorogenic acid A & $Y=16.612 X+16.356$ & 0.9995 & $0.01 \sim 3.10$ \\
9 & Isochlorogenic acid C & $Y=16.103 X+35.311$ & 0.9993 & $0.01 \sim 4.00$ \\
10 & Tween-80 & $Y=1.5269 X+7.5201$ & 0.9988 & $0.50 \sim 4.23$ \\
11 & 5-HT & $Y=0.5468 X-3.5868$ & 0.9989 & $0.03 \times 10^{-3} \sim 3.00 \times 10^{-3}$ \\
\hline
\end{tabular}

14 groups and used and a modified anaphylaxis examination method was established according to the Guidelines for Safety Tests on TCM Injections in the appendix of Chinese Pharmacopoeia 2010. Each guinea pig was subcutaneously injected with $0.2 \mathrm{~mL}$ solution of the test solution (saline, egg albumin, ultrafiltered Reduning injection, unfiltered Reduning injection, Tween-80, chlorogenic acid, geniposide, caffeic acid, neochlorogenic acid, cryptochlorogenin acid, isochlorogenic acid $\mathrm{A}$, isochlorogenic acid $\mathrm{B}$, isochlorogenic acid $\mathrm{C}$, and secoxyloganin) once every other day (three times in total) to test for sensitization. On the 16th day after the first injection, $10 \%$ chloral hydrate $(0.3 \mathrm{~mL} / 100 \mathrm{~g})$ was used to anesthetize the guinea pigs. Animals were stimulated by jugular vein injection with $0.5 \mathrm{~mL}$ solution of each test solutions, respectively. Blood $(1 \mathrm{~mL})$ was extracted from the carotid artery and collected in a heparin anticoagulation tube before (sample A) and after (sample B) the stimulation, and the samples after the stimulation were collected at $30 \mathrm{~min}$. Blood samples were centrifuged at 4,000 rpm for $5 \mathrm{~min}$ and the plasma was stored at $-80^{\circ} \mathrm{C}$.

2.7. Detection of 5-HT. Plasma sample $(100 \mu \mathrm{L})$ was thawed in the dark and mixed by vortex with an equal amount of methanol. The mixture was centrifuged at 3,000 rpm for $10 \mathrm{~min}$. After freezing for $30 \mathrm{~min}$, the solution was centrifuged at $1,000 \mathrm{rpm}$ for $10 \mathrm{~min}$ and $20 \mu \mathrm{L}$ supernatant was used for detection.

Waters 510 liquid chromatograph was used with a Waters 2465 electrochemical detector (Massachusetts, USA) and EC 2000 chromatographic work station (Dalian, China). Hedera ODS-2 chromatographic column $(150 \mathrm{~mm} \times 4.6 \mathrm{~mm}$, $5 \mu \mathrm{m}$, Jiangsu Hanbang Science \& Technology Co., Ltd.) was utilized at a column temperature of $25^{\circ} \mathrm{C}$. Mobile phase was $25 \mathrm{mmol} / \mathrm{L}$ sodium dihydrogen phosphate (containing $0.5 \mathrm{mmol} / \mathrm{L}$ EDTA and $3 \mathrm{mmol} / \mathrm{L}$ sodium heptanesulfonate, $\mathrm{pH}$ 4.6) mixed with acetonitrile at a volume ratio of $85: 15$. The flow velocity was $0.8 \mathrm{~mL} / \mathrm{min}$. ISAAC (in situ silver/silver chloride) was used as the reference electrode. The detection potential was $0.6 \mathrm{~V}$ and the injection volume was $20 \mu \mathrm{L}$. The amount variation rate of 5-HT was calculated according to the following equation:

$$
\text { Sample }(\%)=\frac{(\text { value } B-\text { value } A)}{\text { value } A} \times 100 \% \text {, }
$$

where value $B$ is the amount of $5-\mathrm{HT}$ in sample $B$ and value $\mathrm{A}$ is the amount of $5-\mathrm{HT}$ in sample A.

2.8. Statistical Analysis. Data were reported as mean \pm SD for each group. All statistical analyses were performed using PRISM version 5.0 (GraphPad). Differences with $P$ value of less than 0.5 were considered statistically significant.

\section{Results}

3.1. Calibration Curves of the Investigated Compounds. The mixture of standard solutions, Tween-80, and 5-HT reference solution were diluted to different concentrations. We assigned the compound concentration as the horizontal axis $(X)$ and the peak area as the vertical axis $(Y)$ and performed a linear regression to obtain the regression equations of each component. The results are shown in Table 2. The results showed that for all the standard solutions, there is a good linear relationship between the compound concentration and the area under the peak within a wide range.

The method precision was evaluated by intraday and interday variability. The intraday variability was performed by injection of the same sample six times in the same day. The interday variability was evaluated on two successive days using the same sample. The RSD values are summarized in Table 3. From the results, RSDs for intraday and interday precisions did not exceed $3 \%$. To confirm the repeatability of the method, six independently prepared solutions from the same sample were analyzed. The stabilities of the sample solutions were analyzed at $0,2,4,8,12$, and $24 \mathrm{~h}$ at room temperature. It was found that the sample solutions were stable within $24 \mathrm{~h}$. Precision, repeatability, and stability of nine compounds $(n=6)$, the RSD values, are summarized in Table 3. 
TABLE 3: Precision, repeatability, and stability of nine compounds $(n=6)$.

\begin{tabular}{|c|c|c|c|c|c|}
\hline \multirow[b]{2}{*}{ Serial number } & \multirow[b]{2}{*}{ Component name } & \multicolumn{2}{|c|}{ Precision $(n=6)$} & \multirow[b]{2}{*}{$\begin{array}{c}\text { Repeatability } \\
(n=6) \operatorname{RSD}(\%)\end{array}$} & \multirow{2}{*}{$\begin{array}{c}\text { Stability }(n=6) \\
\text { RSD }(\%)\end{array}$} \\
\hline & & $\begin{array}{c}\text { Intraday RSD } \\
(\%)\end{array}$ & $\begin{array}{c}\text { Interday RSD } \\
(\%)\end{array}$ & & \\
\hline 1 & Neochlorogenic acid & 1.32 & 1.46 & 2.01 & 1.56 \\
\hline 2 & Chlorogenic acid & 1.78 & 2.74 & 2.39 & 2.44 \\
\hline 3 & Cryptochlorogenin acid & 1.42 & 2.03 & 2.72 & 2.75 \\
\hline 4 & Caffeic acid & 1.09 & 1.62 & 2.47 & 2.05 \\
\hline 5 & Geniposide & 2.07 & 1.98 & 1.59 & 1.46 \\
\hline 6 & Secoxyloganin & 2.01 & 2.41 & 2.84 & 2.26 \\
\hline 7 & Isochlorogenic acid B & 1.37 & 1.93 & 1.23 & 1.74 \\
\hline 8 & Isochlorogenic acid $\mathrm{A}$ & 1.96 & 2.34 & 2.68 & 1.35 \\
\hline 9 & Isochlorogenic acid C & 1.79 & 2.63 & 1.86 & 1.90 \\
\hline 10 & Tween-80 & 2.67 & 2.83 & 2.40 & 2.58 \\
\hline 11 & 5-HT & 1.39 & 1.57 & 1.82 & 1.66 \\
\hline
\end{tabular}

TABLE 4: Recovery of the compounds in Reduning injection.

\begin{tabular}{|c|c|c|c|c|c|c|}
\hline Serial number & Compounds & Contained $(\mathrm{mg} / \mathrm{mL})$ & Added $(\mathrm{mg} / \mathrm{mL})$ & Found mean $(\mathrm{mg} / \mathrm{mL})$ & Recovery mean (\%) & $\operatorname{RSD}(\%) n=6$ \\
\hline 1 & Neochlorogenic acid & 3.68 & 3.56 & 7.09 & 104.39 & 2.36 \\
\hline 2 & Chlorogenic acid & 5.83 & 5.93 & 11.98 & 96.42 & 1.87 \\
\hline 3 & Cryptochlorogenin acid & 3.30 & 3.24 & 6.49 & 101.56 & 1.94 \\
\hline 4 & Caffeic acid & 0.34 & 0.34 & 0.67 & 103.03 & 2.50 \\
\hline 5 & Geniposide & 8.95 & 8.79 & 17.93 & 97.88 & 1.69 \\
\hline 6 & Secoxyloganin & 1.01 & 0.98 & 2.04 & 95.14 & 2.15 \\
\hline 7 & Isochlorogenic acid B & 0.62 & 0.59 & 1.19 & 103.50 & 2.36 \\
\hline 8 & Isochlorogenic acid A & 0.32 & 0.32 & 0.65 & 96.96 & 2.13 \\
\hline 9 & Isochlorogenic acid C & 0.52 & 0.50 & 1.03 & 98.03 & 1.98 \\
\hline 10 & Tween-80 & 2.20 & 2.00 & 4.25 & 97.56 & 2.69 \\
\hline 11 & 5-HT & $0.091 \times 10^{-3}$ & $0.092 \times 10^{-3}$ & $0.186 \times 10^{-3}$ & 96.84 & 2.87 \\
\hline
\end{tabular}

The recovery was evaluated by adding standards into the sample. The mixture was extracted and analyzed by using the above method. Six replicates were performed for the determination. The RSD values are summarized in Table 4.

HPLC chromatogram of the standard solution mixture was shown in Figure 1, the chromatogram of Tween-80 reference solution was shown in Figure 2. The chromatogram of Reduning injection was shown in Figure 3.

3.2. Percentage of Retention of Major Components after Ultrafiltration. An ultrafiltration membrane was used to filter the Reduning injection. The permeation of molecular through the membranes was not entirely related to the monomolecular weight of composition, but to the molecular's existence formed (monomolecular, low polymolecular, and high polymolecular) in the solution. The concentrations and percentage of retention of the major components contained in the injection both before and after ultrafiltration are shown in Table 5. The percentage of retention of chlorogenic acid, geniposide, caffeic acid, neochlorogenic acid, and cryptochlorogenin acid is all greater than 90\%, while the percentage of retention of secoxyloganin, isochlorogenic acid $\mathrm{A}$, isochlorogenic acid $\mathrm{B}$, and isochlorogenic acid $\mathrm{C}$ is all

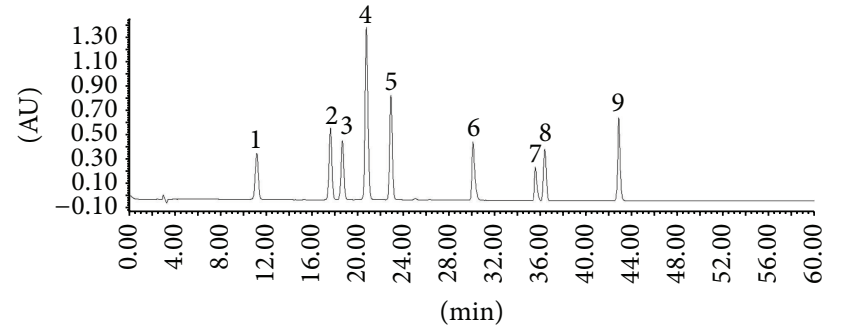

FIGURE 1: HPLC chromatograms of standard solution of nine compounds: (1) neochlorogenic acid; (2) chlorogenic acid; (3) cryptochlorogenin acid; (4) caffeic acid; (5) geniposide; (6) secoxyloganin; (7) isochlorogenic acid B; (8) isochlorogenic acid A; (9) isochlorogenic acid C.

greater than $70 \%$. The percentage of retention of Tween-80 is $20 \%$.

3.3. Plasma 5-HT in Guinea Pigs. The chromatogram of 5-HT was shown in Figure 4. After the guinea pigs were sensitized to saline for $30 \mathrm{~min}$ by injection, the average increasing rate of plasma 5 -HT was $4.46 \%$. The average increasing 
TABLE 5: Concentration and percentage of retention of each component before and after ultrafiltration.

\begin{tabular}{|c|c|c|c|c|c|}
\hline Serial number & Name & $\begin{array}{c}\text { Before } \\
\text { ultrafiltration } \\
(\mathrm{mg} / \mathrm{mL})\end{array}$ & $\begin{array}{l}\text { After ultrafiltration } \\
\qquad(\mathrm{mg} / \mathrm{mL})\end{array}$ & $\begin{array}{l}\text { Percentage of } \\
\text { retention }(\%)\end{array}$ & $\begin{array}{c}\text { RSD } \\
(\%) \\
n=3 \\
\end{array}$ \\
\hline 1 & Neochlorogenic acid & 3.71 & 3.42 & $92.18^{* *}$ & 1.79 \\
\hline 2 & Chlorogenic acid & 6.12 & 5.46 & $89.21^{* *}$ & 2.25 \\
\hline 3 & Cryptochlorogenin acid & 3.32 & 3.00 & $90.36^{* *}$ & 2.12 \\
\hline 4 & Caffeic acid & 0.31 & 0.29 & $93.54^{* *}$ & 2.10 \\
\hline 5 & Geniposide & 9.10 & 8.90 & $97.80^{* *}$ & 1.63 \\
\hline 6 & Secoxyloganin & 1.02 & 0.68 & $73.67^{* *}$ & 2.13 \\
\hline 7 & Isochlorogenic acid B & 0.60 & 0.44 & $73.33^{* *}$ & 1.98 \\
\hline 8 & Isochlorogenic acid $\mathrm{A}$ & 0.33 & 0.25 & $75.76^{* *}$ & 2.43 \\
\hline 9 & Isochlorogenic acid C & 0.51 & 0.36 & $70.58^{* *}$ & 1.59 \\
\hline 10 & Tween-80 & 2.00 & 0.40 & 20.00 & 2.58 \\
\hline
\end{tabular}

Values are expressed as mean $\pm \mathrm{SD} ; n=3$ in each group. ${ }^{* *} P<0.01$ versus Tween-80 group.

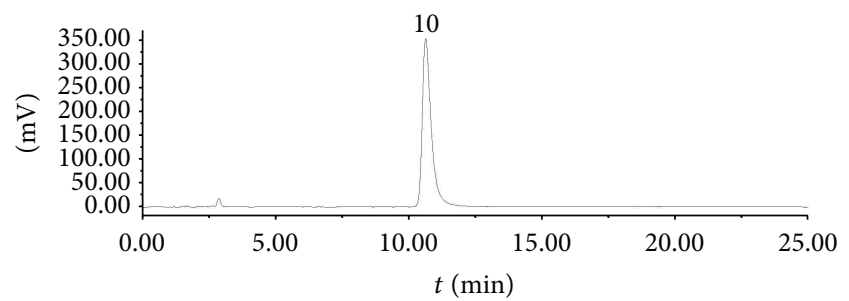

Figure 2: HPLC chromatograms of Tween-80.

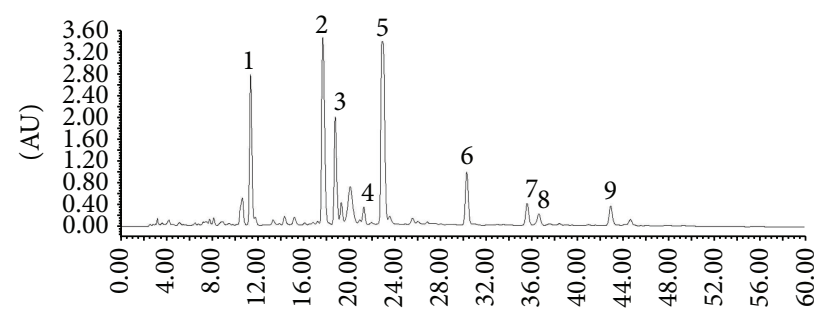

(min)

FIGURE 3: The chromatogram of Reduning injection: (1) neochlorogenic acid; (2) chlorogenic acid; (3) cryptochlorogenin acid; (4) caffeic acid; (5) geniposide; (6) secoxyloganin; (7) isochlorogenic acid $\mathrm{B} ;(8)$ isochlorogenic acid $\mathrm{A}$; (9) isochlorogenic acid C.

rate in plasma 5-HT content following sensitization to egg albumin, unfiltered Reduning, Tween-80, chlorogenic acid, and cryptochlorogenin acid were significant, ranging from $37.75 \%$ to $48.11 \%$. In contrast, then, the guinea pigs were sensitized to Reduning ultrafiltrate; the average increasing rate in plasma $5-\mathrm{HT}$ was reduced significantly compared to unfiltered Reduning. The average increase rate in plasma 5HT following sensitization to neochlorogenic acid, geniposide, caffeic acid, secoxyloganin, and all three isochlorogenic acid isomers were all below $10 \%$. Each group of data and sodium chloride injection group were conducted with oneway ANOVA, the results of which were shown in Figure 5.

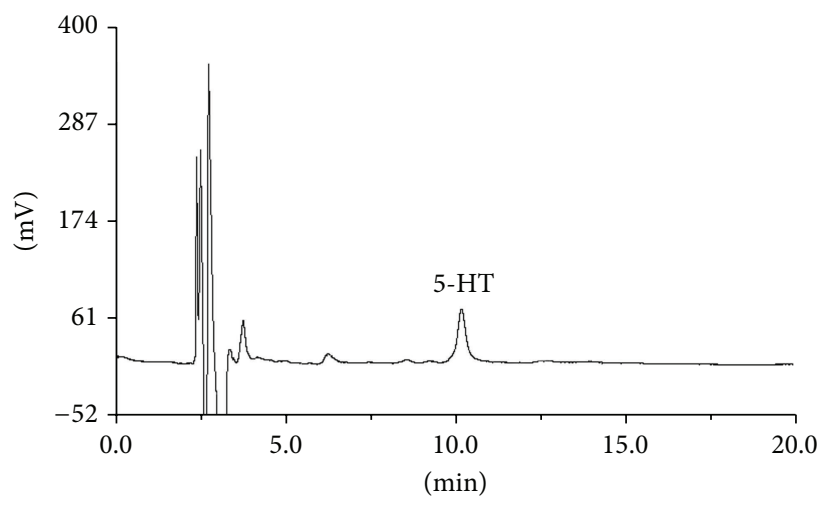

Figure 4: The chromatogram of 5-HT.

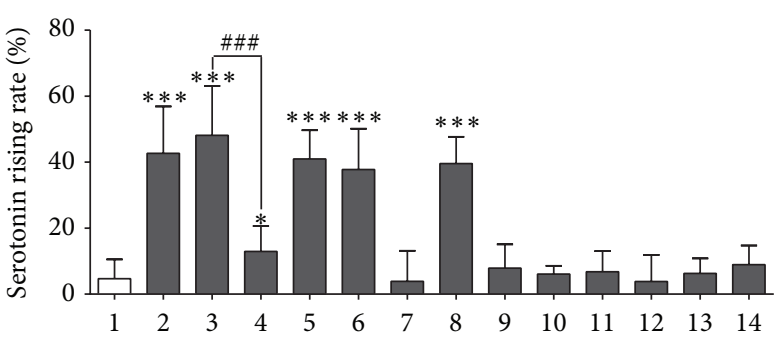

FIGURE 5: Increasing rate of 5-HT in guinea pig plasma; (1) saline; (2) egg albumin; (3) Reduning injection; (4) filtered Reduning injection; (5) Tween-80; (6) chlorogenic acid; (7) neochlorogenic acid; (8) cyclohexanecarboxylic acid; (9) gardenoside; (10) caffeic acid; (11) isochlorogenic acid A; (12) isochlorogenic acid B; (13) isochlorogenic acid C; (14) secoxyloganin. Values are expressed as mean \pm SD; $n=10$ in each group. ${ }^{*} P<0.05$, and ${ }^{* * *} P<0.001$ versus saline. ${ }^{\# \# \#} P<0.001$ versus filtered Reduning injection.

\section{Discussion}

Allergic reaction is the most common adverse reaction of herbal injection which could lead to life-threatening health problems. Commonly used methods such as murine passive 
cutaneous anaphylaxis and measurement of the antibodies were expensive and time-consuming work. Previous studies have identified two types of antibody-mediated systemic anaphylaxis; one is mediated by IgE and the other mediated by IgG [20-23]. Mast cells are the major effector cells of IgE mediated in allergic reaction and play a key role in allergic reaction diseases [24]; when anaphylactic reaction occurs, mast cells and basophils would degranulate and release $\beta$ hexosaminidase, histamine, serotonin, or other cytokines [25-28]. In this study, a simple and rapid method was discussed based on the measurement of serotonin with HPLC technique for predicting allergenic reaction of all the analytes.

Previous studies have reported that the chlorogenic acid in honeysuckle may cause anaphylaxis $[29,30]$. In present study, we investigated sensitization to the major phenolic acid components in Reduning injection in guinea pigs. Our results indicate that chlorogenic acid causes sensitization, which is consistent with previous reports. At the same time, we found that cryptochlorogenin acid also could cause anaphylactoid reaction even stronger than chlorogenic acid. Other components, such as caffeic acid, neochlorogenic acid, isochlorogenic acid $\mathrm{A}$, isochlorogenic acid $\mathrm{B}$, isochlorogenic acid $\mathrm{C}$, and secoxyloganin do not induce obvious sensitization. However, concentration of chlorogenic acid and cryptochlorogenin acid in filtered Reduning is similar to its concentration before ultrafiltration, yet we detected obvious sensitization in guinea pigs using unfiltered Reduning while ultrafiltered Reduning exhibited no significant sensitization, suggesting that there is a remarkable difference between sensitizations to chlorogenic acid and cryptochlorogenin acid as an isolated compound and as a component in a mixed solution. The difference can likely be attributed to the form of chlorogenic acid and cryptochlorogenin acid within the complex solution mixture. In herbal medicine solution, the compounds exist in many forms such as ionic, molecular, and associated.

Tween-80 is a nonionic detergent and is mostly used in Chinese medicine injections to assist in solubilization $[31,32]$. However, adverse reactions of Tween- 80 have been observed with time. There are several Chinese medicine injections in clinical use that contain Tween-80, such as Yuxingcao injection and Xiangdan injection, both of which have been reported to have serious adverse reactions [13]. The percentage of retention of Tween-80 in ultrafiltered Reduning injection was low, resulting in decreased Tween-80 and decreased sensitization, which suggests that any observed sensitization to Reduning injection was likely due to the presence of Tween-80.

\section{Conclusions}

In this study, a simple HPLC technique was successfully used for predicting allergenic reaction of all the analytes in Reduning injection before and after ultrafiltration and we suggested that Tween- 80 might be the cause of anaphylaxis. Additionally, the form of chlorogenic acid and cryptochlorogenin acid within the complex solution mixture may also affect the sensitizing effect of them. Our findings might contribute to the safety evaluation of Reduning injection in clinical medication.

\section{Disclosure}

Cun-yu Li is the co-first author of this paper.

\section{Conflict of Interests}

The authors declare that there is no conflict of interests.

\section{Acknowledgments}

This work is supported by the Specialized Research Fund for the Doctoral Program of Higher Education of China (no. 20123237110009), the National Natural Science Foundation of China (Grant no. 81503258), Youth Natural Science Foundation of Jiangsu province (Grant no. BK20151005), Science and Technology Project of Jiangsu Traditional Chinese Medicine Administration (Grant no. YB2015009), and the Grant from the National Science Foundation of China (no. 81373980).

\section{References}

[1] W. Xiao, Y. Ling, Y.-A. Bi, Z.-Z. Wang, and C.-F. Zhang, "GC/MS fingerprint of Reduning injection," Chinese Journal of Natural Medicines, vol. 5, no. 2, pp. 127-129, 2007.

[2] Y. X. Wang, T. Liu, Z. Z. Wang, J. Zhang, and W. Xiao, "Compatible stability of reduning injection with solvents," Zhongguo Zhong Yao Zazhi, vol. 35, no. 22, pp. 2990-2993, 2010.

[3] L. M. Sun, X. C. Chang, R. B. Zhao, Y. L. Cui, and L. J. Wang, "Reduning treatment of children with herpes angina efficacy," China Medical Herald, vol. 8, article 149, 2011.

[4] G. Z. Feng, F. Zhou, and M. Huang, "Anti-respiratory syncytial virus (RSV, Long strain) effects of Reduning injection in vitro," Acta Universitatis Medicinalis Nanjing, vol. 27, pp. 1009-1012, 2007.

[5] Y.-J. Li, Z.-Z. Wang, Y.-A. Bi et al., "The evaluation and implementation of direct analysis in real time quadrupole timeof-flight tandem mass spectrometry for characterization and quantification of geniposide in Re du Ning Injections," Rapid Communications in Mass Spectrometry, vol. 26, no. 11, pp. 1377$1384,2012$.

[6] H. M. Xu, Y. Wang, and N. F. Liu, "Safety of an injection with a mixture of extracts from Herba Artemisiae annuae, Fructus Gardeniae and Flos Lonicerae," Pharmacy World and Science, vol. 31, no. 4, pp. 458-463, 2009.

[7] J. C. Liang, Y. K. Huang, Z. Cai, and L. Jiang, "Determination of chlorogenic acid and geniposide in reduning injection by HPLC," Chinese Journal of New Drugs, vol. 17, article 18, 2008.

[8] Y. Li, P. Wang, W. Xiao, L. Zhao, Z. Wang, and L. Yu, "Screening and analyzing the potential bioactive components from reduning injection, using macrophage cell extraction and ultra-high performance liquid chromatography coupled with mass spectrometry," The American Journal of Chinese Medicine, vol. 41, no. 1, pp. 221-229, 2013.

[9] Y. A. Bi, Z. Z. Wang, A. H. Song, T. Liu, X. H. Fu, and W. Xiao, "The fingerprint research and multi-component qualitative analysis of reduning injection via HPLC," World Science and Technology, vol. 2, pp. 11-13, 2010. 
[10] W. L. Li, Z. W. Cheng, Y. F. Wang, and H. B. Qu, "Quality control of Lonicerae Japonicae Flos using near infrared spectroscopy and chemometrics," Journal of Pharmaceutical and Biomedical Analysis, vol. 72, pp. 33-39, 2013.

[11] L. Zeng, M. Wang, Y. Yuan et al., "Simultaneous multicomponent quantitation of Chinese herbal injection Yin-zhihuang in rat plasma by using a single-tube extraction procedure for mass spectrometry-based pharmacokinetic measurement," Journal of Chromatography B, vol. 967, pp. 245-254, 2014.

[12] J.-X. Ye, W. Wei, L.-H. Quan, C.-Y. Liu, Q. Chang, and Y.-H. Liao, "An LC-MS/MS method for the simultaneous determination of chlorogenic acid, forsythiaside A and baicalin in rat plasma and its application to pharmacokinetic study of Shuanghuang-lian in rats," Journal of Pharmaceutical and Biomedical Analysis, vol. 52, no. 4, pp. 625-630, 2010.

[13] K. Ji, J. Chen, M. Li et al., "Comments on serious anaphylaxis caused by nine Chinese herbal injections used to treat common colds and upper respiratory tract infections," Regulatory Toxicology and Pharmacology, vol. 55, no. 2, pp. 134-138, 2009.

[14] X. L. Zhi, C. Y. Li, H. Y. Li, and G. P. Peng, "Depyrogenation mechanism of baicalin solution with activated carbon," Asian Journal of Chemistry, vol. 25, no. 15, pp. 8821-8824, 2013.

[15] H. M. Li, C. Y. Li, Y. F. Zheng et al., "Effect of solution factors on endotoxin coagulation state," Asian Journal of Chemistry, vol. 25, no. 12, pp. 6915-6919, 2013.

[16] E. D. Quakkelaar, M. F. Fransen, W. W. C. Van Maren et al., "IgG-mediated anaphylaxis to a Synthetic long peptide vaccine containing a B cell epitope can be avoided by slow-release formulation," The Journal of Immunology, vol. 192, no. 12, pp. 5813-5820, 2014.

[17] V. Chirico, A. Lacquaniti, S. Vinci et al., "High-mobility group box 1 in allergic and non-allergic upper airway inflammation," Journal of Biological Regulators \& Homeostatic Agents, vol. 29, no. 2, supplement 1, pp. 55-57, 2015.

[18] S. H. Park, H.-J. Choi, S. Y. Lee, and J.-S. Han, "TLR4mediated IRAK1 activation induces TNF- $\alpha$ expression via JNKdependent NF- $\kappa \mathrm{B}$ activation in human bronchial epithelial cells," European Journal of Inflammation, vol. 13, no. 3, pp. 183195, 2015.

[19] L. Yu, G. Peng, C. Li et al., "A rapid and low-cost approach to evaluate the allergenicity of herbal injection using HPLC analysis," Fitoterapia, vol. 88, pp. 12-18, 2013.

[20] J. Y. Oh, W.-S. Choi, C. H. Lee, and H.-J. Park, "The ethyl acetate extract of Cordyceps militaris inhibits IgE-mediated allergic responses in mast cells and passive cutaneous anaphylaxis reaction in mice," Journal of Ethnopharmacology, vol. 135, no. 2, pp. 422-429, 2011.

[21] I. Miyajima, D. Dombrowicz, T. R. Martin, J. V. Ravetch, J. P. Kinet, and S. J. Galli, "Systemic anaphylaxis in the mouse can be mediated largely through IgG1 and Fc $\gamma$ RIII. Assessment of the cardiopulmonary changes, mast cell degranulation, and death associated with active or IgE- or IgG1-dependent passive anaphylaxis," Journal of Clinical Investigation, vol. 99, no. 5, pp. 901-914, 1997.

[22] R. T. Strait, S. C. Morris, M. Yang, X.-W. Qu, and F. D. Finkelman, "Pathways of anaphylaxis in the mouse," Journal of Allergy and Clinical Immunology, vol. 109, no. 4, pp. 658-668, 2002.

[23] W. Jacoby, P. V. Cammarata, S. Findlay, and S. H. Pincus, "Anaphylaxis in mast cell-deficient mice," Journal of Investigative Dermatology, vol. 83, no. 4, pp. 302-304, 1984.
[24] W. H. Huang, X. Luo, and L. Zhou, "Mast cell degranulation of Qing Kai Ling injection on RBL-2H3," Journal of Guiyang College of Traditional Chinese Medicine, vol. 32, article 80, 2010.

[25] F. Huang, X. Tong, H. Deng, L. Fu, and R. Zhang, "Inhibition of the antigen-induced activation of RBL-2H3 cells by Gab2 siRNA," Cellular and Molecular Immunology, vol. 5, no. 6, pp. 433-438, 2008.

[26] T. Y. Shin, J. H. Park, and H. M. Kim, "Effect of Cryptotympana atrata extract on compound 48/80-induced anaphylactic reactions," Journal of Ethnopharmacology, vol. 66, no. 3, pp. 319-325, 1999.

[27] T. C. Theoharides, P. K. Bondy, N. D. Tsakalos, and P. W. Askenase, "Differential release of serotonin and histamine from mast cells," Nature, vol. 297, no. 5863, pp. 229-231, 1982.

[28] M. K. Church and F. Levi-Schaffer, "The human mast cell," Journal of Allergy and Clinical Immunology, vol. 99, no. 2, pp. 155-160, 1997.

[29] S. O. Freedman, R. Shulman, J. Krupey, and A. H. Sehon, "Antigenic properties of chlorogenic acid," Journal of Allergy, vol. 35, no. 2, pp. 97-107, 1964.

[30] G. N. Xiao, Q. P. Sun, and H. A. Chen, "Contribution of serum IL-4 and IgE to the early prediction of allergic reactions induced by chlorogenic acid," European Journal of Pharmacology, vol. 699, no. 1-3, pp. 1-5, 2013.

[31] H. Riehm and J. L. Biedler, "Potentiation of drug effect by Tween-80 in Chinese hamster cells resistant to actinomycin D and daunomycin," Cancer Research, vol. 32, pp. 1195-1200, 1972.

[32] A. Kellner, J. W. Correll, and A. T. Ladd, "Sustained hyperlipemia induced in rabbits by means of intravenously injected surface-active agents," The Journal of Experimental Medicine, vol. 93, no. 4, pp. 373-384, 1951.

[33] F. Jin, Y. Qu, Y. Guan, and M. Cai, "8 Cases literature analysis of anaphylactic shock induced by Xiangdan injection," Chinese Journal of Pharmacovigilance, vol. 8, no. 6, pp. 376-378, 2011. 


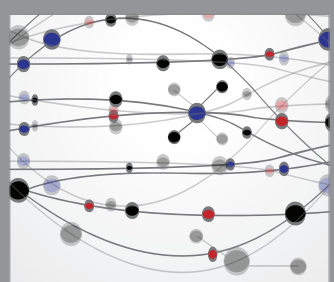

The Scientific World Journal
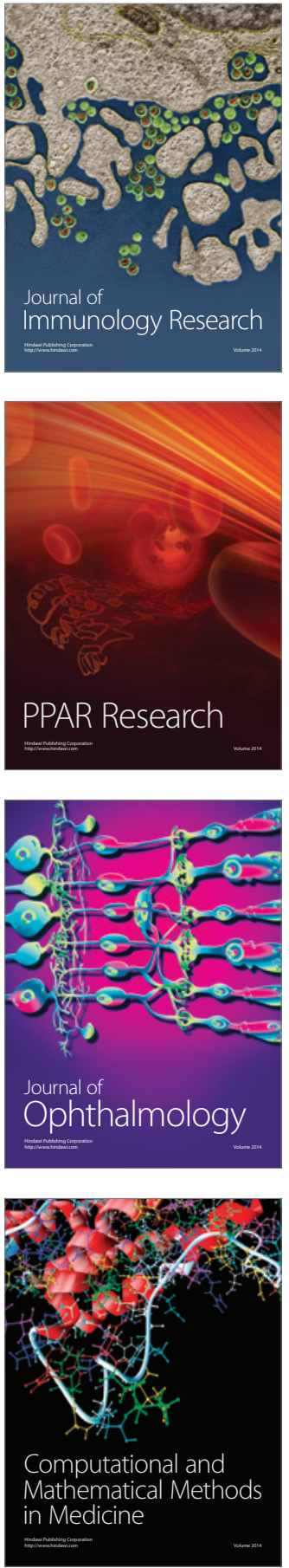

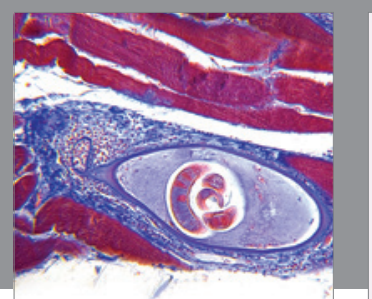

Gastroenterology Research and Practice

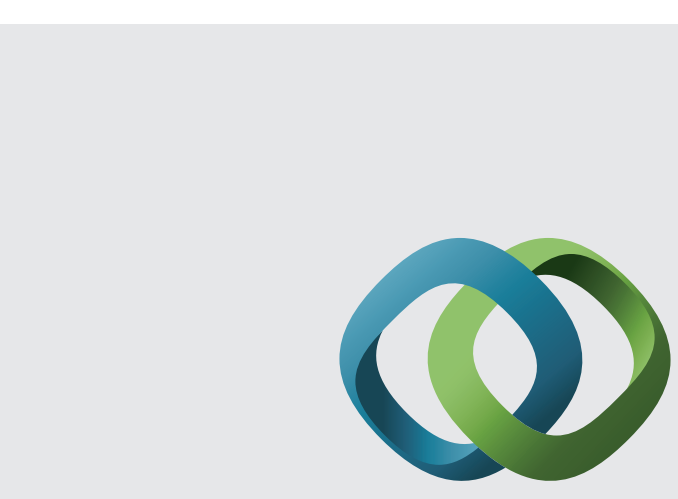

\section{Hindawi}

Submit your manuscripts at

http://www.hindawi.com
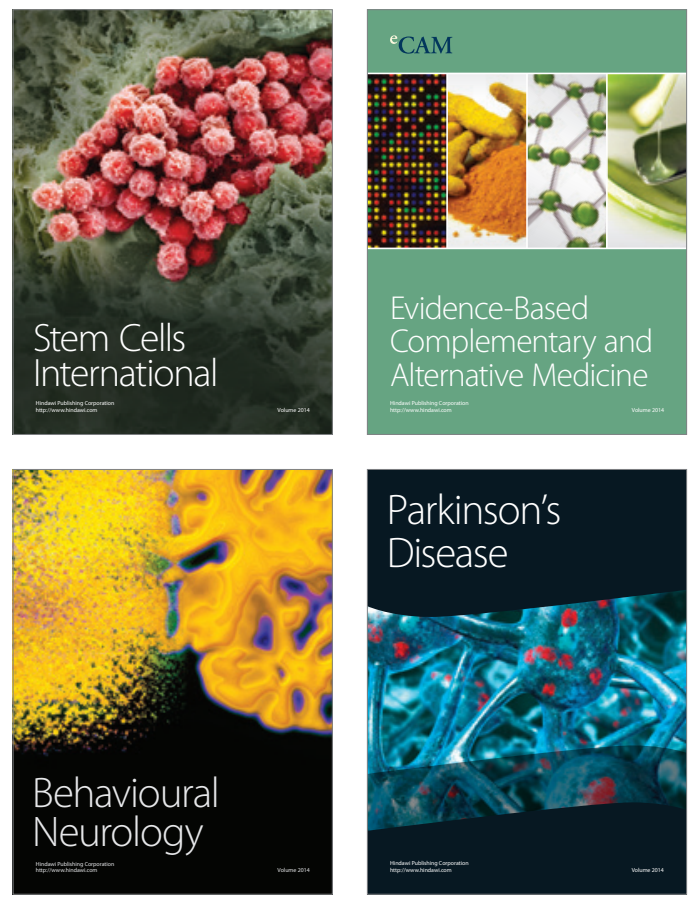
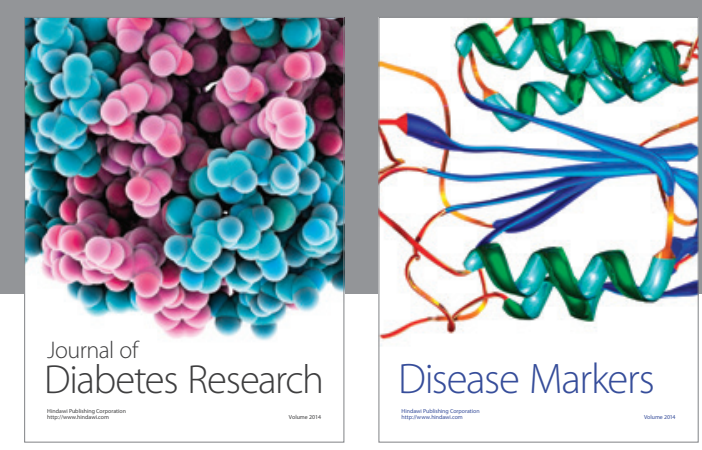

Disease Markers
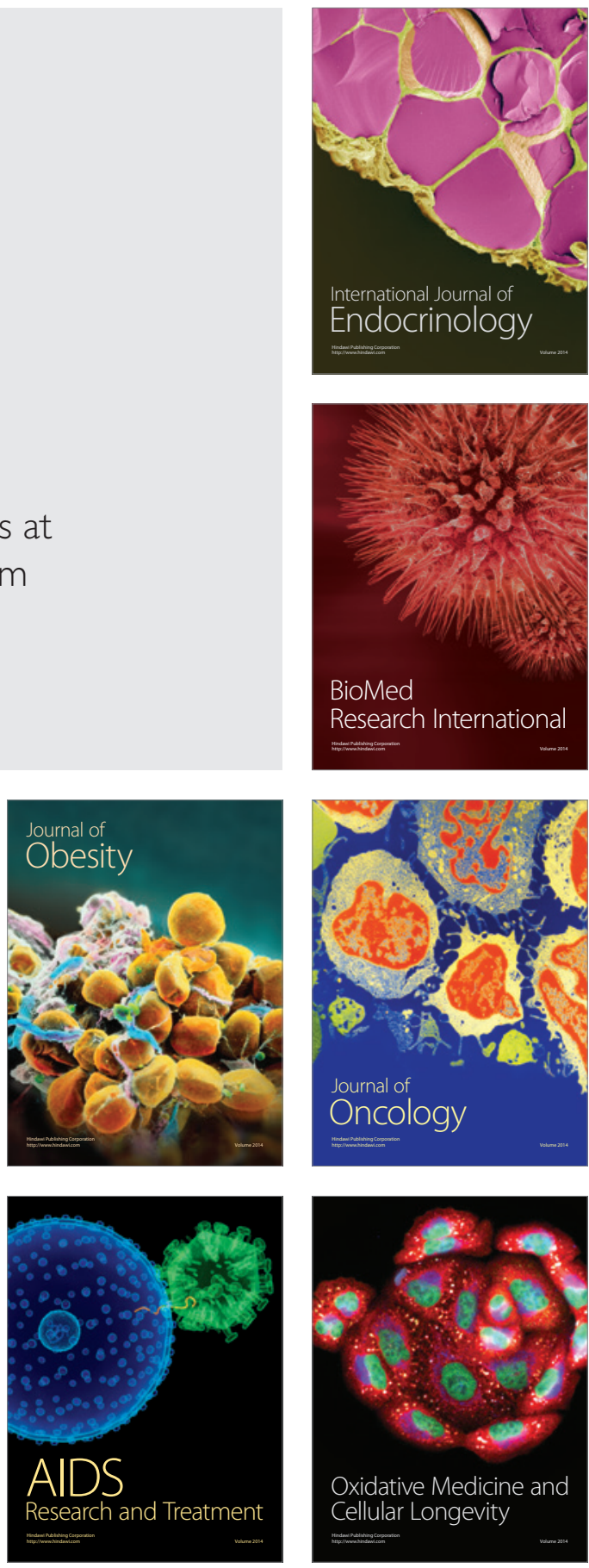